Geopolítica(s) Revista de estudios sobre espacio y poder ISSN: 2172-3958

https://dx.doi.org/10.5209/geop.78609

\title{
Reflexiones y actualidad de la Geografía Política mexicana
}

Samuel Schmidt, Verónica Ibarra y Gonzalo Hatch (2020) México visto desde una geografia política. México: Universidad Nacional Autónoma de México, 222 pp. ISBN 978-607-30-3592-7.

Las condiciones sociales, políticas, económicas y ambientales a nivel global plantean una serie de cuestionamientos e incertidumbres acerca del futuro en el plazo inmediato, siendo las Ciencias Sociales en su conjunto las que tienen la responsabilidad de abordarlas y contribuir a su resolución o cuanto menos a su comprensión. Esto requiere de análisis que integren diferentes perspectivas dada su naturaleza compleja donde las relaciones de poder deben estar siempre presente en el análisis, siendo la Geografía Política una de las disciplinas que toma para si su estudio. En este libro se presenta un esfuerzo colectivo que resulta de gran valor para conocer la actualidad de la Geografía Política mexicana a través de estudios de caso donde se aplican categorías analíticas de diversa índole.

Los coordinadores del libro reconocen la importancia de adoptar un enfoque interdisciplinar en la Geografía Política, en tanto permitiría problematizar los procesos espaciales que se desarrollan en distintas escalas y que requieren de un abordaje integral. Al mismo tiempo, establecen un distanciamiento clave entre la geografía y el resto de las Ciencias Sociales, destacando aspectos como la creatividad, la curiosidad y la imaginación en temas comúnmente ignorados o abordados de forma limitada, siendo los seis capítulos de la obra un buen ejemplo de aportes teóricos, metodológicos y conceptuales en estudios de caso que abarcan desde el deporte, la participación ciudadana, el género o la gestión de aguas transfronterizas.

En el primer capítulo, Verónica Ibarra elabora una cronología de la evolución de la Geografía Política, así como su interés por el abordaje de temáticas cada vez más novedosas en México durante el siglo XX en donde se destacan hitos en los cuales la noción que se utilizaba del espacio ha sufrido importantes modificaciones, pasando de una perspectiva cartesiana del espacio como un mero contenedor a una perspectiva relacional más compleja. Desde sus orígenes en la geografía alemana con Ratzel, pasando por las discusiones en las escuelas francesas con Paul Claval y la escuela anglosajona con Peter J. Taylor, entre otros, la disciplina se ha visto influenciada por las diferentes herramientas técnicas y metodologías, así como por los aportes conceptuales de distintas procedencias, siendo de relevancia la incorporación del debate iniciado en torno a la producción del espacio planteado por Henri Lefebvre. 
La geografía mexicana no figuró en los análisis políticos de las décadas 1960 y 1970, lo cual orilló a la Geografía Política a "la memorización de capitales, fronteras y a una naturalización de los procesos sociales y políticos" (p.30) hasta la llegada de Graciela Uribe en la década de los 1980, quien contribuyó a asentar el desarrollo de la disciplina en el Colegio de Geografía de la UNAM, cuyas reflexiones se vieron beneficiadas por el intercambio y el debate con otras disciplinas, principalmente la filosofía de corte marxista (con autores como Enrique Dussel, Bolívar Echeverría y Adolfo Sánchez Vásquez, con quienes compartió aulas en la misma facultad). Al final de este recorrido teórico-histórico se establece que la disciplina ha tomado para sí el análisis de las estructuras y las relaciones de poder, así como los conflictos y tensiones por apropiación y el sentido del espacio social con la flexibilidad del análisis multiescalar. Ello ha supuesto una importante distinción con la geopolítica, que más que una disciplina, ha fungido como una ideología belicista cuya lamentable confusión ha obstaculizado la difusión de la Geografía Política en México, algo que este libro puede contribuir a superar.

En el capítulo de Gonzalo Hatch y Joel Carrillo se presenta el estudio de las asimetrías existentes en la gestión de las aguas subterráneas transfronterizas compartidas entre México y los Estados Unidos. Estos flujos no coinciden con las fronteras políticas al ser meras convenciones administrativas, por lo que su gestión supone un desafío de múltiples aristas que van más allá de sus dimensiones físicas. Desde su lectura, los estudios y trabajos realizados hasta la fecha en el acuífero transfronterizo "Río San Pedro" aún evidencian una clara falta de dimensiones adecuadas y suficientes para lograr una evaluación integral que considere aspectos científico-técnicos, jurídicos y de políticas públicas, neurálgicos para este fin. Más aun, establecen que desde las ciencias sociales se ha abordado de forma muy incipiente el hecho de que una "deficiente evaluación hidrogeológica representa un punto crítico en la configuración de conflictos políticos y ambientales" (p.38) con el país vecino, particularmente en un contexto de cambio climático y de contingencia sanitaria a nivel global, donde las fuentes de agua adquieren un valor estratégico.

El diálogo propuesto entre la Geografía Política y la Hidrogeología permite identificar asimetrías existentes entre ambos países en la gestión de estos sistemas, por lo que recomiendan la producción de información relevante a través de la georreferenciación de pozos, identificación de concesionarios de agua subterránea, volúmenes de extracción, así como indicadores de calidad en tiempo real. De esta forma, vinculan el intercambio de esa información en un clima de honestidad y confianza con la prevención de potenciales conflictos por el uso del agua compartida, lo que contribuiría a generar una gobernanza binacional con un enfoque de seguridad hídrica. Para ello consideran prioritario dejar de considerar al sistema de forma aislada, sino que se tomen en cuenta los flujos locales, intermedios y regionales propuestos por Toth, incentivando al mismo tiempo la formación de profesionales mexicanos expertos en la materia

En el capítulo de Iracema Gavilán se estudia el conflicto asociado a la actividad minera en Wirikuta, un territorio considerado sagrado por la cultura wixarika o huichol en el estado de San Luis Potosí. La autora pone en contexto las problemáticas en territorio potosino como parte de los ajustes del modelo neoliberal y la reproducción del capital a escala global donde la región ha ocupado un rol particular 
como proveedor de commodities. La entidad de estudio históricamente ha estado asociada a la práctica minera desde la época colonial por lo que la estrategia argumentativa de la autora incluye un contraste entre las distintas valoraciones del espacio por parte de los distintos actores involucrados (la comunidad indígena, el Estado, la empresa minera, etc.) a través del cual logra identificar una visión desarrollista del desierto como un espacio vacío y sin valor aparente y otra donde predomina el valor simbólico y la identidad del territorio

Su propuesta consiste en distinguir entre los movimientos socio-espaciales y los socio-territoriales (p.85) distinción que resulta sumamente útil para evidenciar cómo se manifiestan las relaciones de poder en distintas escalas, los actores que intervienen en ellas y los ámbitos que están en disputa. Esto le permite esclarecer los vínculos a nivel local entre el presidente municipal y la empresa First Majestic Silver Corp. que han generado tensiones entre la comunidad indígena, mientras que a escala regional el conflicto se enmarca en una disputa por el flujo de las aguas subterráneas y las distintas valoraciones de este recurso estratégico. A ello añade el establecimiento de alianzas con movimientos sociales afines a la lucha de la comunidad, que ha contribuido a la declaración desde 2016 de Wirikuta como un territorio libre de minería en un "territorio que se alega, por designio debe vivir de la minería" (p.99). Las diferentes valoraciones y discursos en torno al mismo espacio son un elemento central de análisis en este tipo de conflictos, por lo que resulta muy valiosa la presentación de cartografía participativa que funge como complemento visual y analítico de este tipo de procesos.

A continuación, María del Carmen Acosta aborda el vacío existente en las investigaciones geográficas en México con respecto a la geografía electoral desde un enfoque de género. Su propuesta consiste en la evaluación de la presencia femenina en el poder legislativo de carácter federal en el Estado de México a través de diferentes sistemas de representación: el de mayoría relativa y el de representación proporcional.

La representación de mujeres en puestos políticos se ha visto constreñida por la estructura del sistema patriarcal que ha permeado en el sistema de partidos, impidiendo que las mujeres mexicanas puedan ejercer plenamente su ciudadanía, lo cual se puede evidenciar en dos ámbitos: 1) el de las imprecisiones y puesta en práctica de las leyes y marcos jurídicos correspondientes, y 2) al interior de los partidos políticos al ubicar a las mujeres en sitio de suplencia, por lo que comparativamente "la ciudadanía de la mujer diferenciada y degrada, respecto a la de los hombres" (p.140).

El estudio abarca los procesos electorales de 2006, 2009 y 2012 donde se observa un marcado contraste en la dimensión espacial de la representación, siendo las ciudades las que presentan mayor apertura para apoyar a las candidatas, destacando otras variables como cambios en el marco jurídico electoral a través de sanciones a los partidos que no cumplan con la cuota de género. Reconociendo sus importantes impactos, no deja de lado que aún faltan avances más sustanciosos en la materia, al concluir que "el Estado es una institución con género y este es masculino" (p.138).

En el siguiente capítulo Joaquín García y Guillermo Lizama analizan, desde una metodología cualitativa comparada, los mecanismos de participación ciudadana en México a nivel sub-nacional, haciendo énfasis en el estado de Hidalgo. Observan que desde la reforma político-electoral de 2014 se ha configurado una geografía de 
la democracia participativa que varía desde la escala federal hasta la municipal dependiendo de su grado de consideración e implementación el cual presentan a través de cartografía temática. Desde su perspectiva, lo que puede aportar un enfoque desde la Geografía Política es evidenciar la forma a través de la cual "el territorio sustenta prácticas políticas y ciudadanas, volviendo a la idea de que el espacio es producto de relaciones de poder que definen formas de comportamientos en individuos instituciones y la sociedad en torno al campo político" (p.178).

La participación ciudadana es relevante en este sentido pues permite fortalecer el sistema de pesos y contrapesos, empoderando a las personas frente a decisiones públicas, generando incentivos para favorecer un gobierno más cercano a la ciudadanía, todo ello en un marco de crisis de la democracia representativa donde el "ciudadano ordinario no está preparado para tomar decisiones complejas e importantes" (p.179). Señalan que para la solución de estos problemas no basta con la existencia de dichos mecanismos, sino que se requiere el interés de los ciudadanos en asuntos públicos, lo que es difícil dada la falta de confianza hacia las instituciones, lo que redunda en bajos índices de participación ciudadana. Por ello, una de sus principales conclusiones es que el ejercicio de estos mecanismos debe promoverse a nivel local debido a la cercanía entre representantes y representados, lo que puede generar una mejor definición de las políticas públicas resultantes y su evaluación.

En el último capítulo, Jonathan Montero estudia el proceso de movilidad geográfica del Necaxa, un equipo de tradición en el fútbol mexicano profesional. $\mathrm{Su}$ principal interés radica en la comprensión del proceso a través del cual los cambios de residencia y propiedad del equipo han obedecido a los intereses de ciertas élites locales y la forma en que éstas configuran "prácticas, acciones y discursos" (p.215) que se manifiestan espacialmente. A través de la evolución histórica del equipo se movilizan valores simbólicos de distintas formas aprovechando sus funciones como elemento identitario y de cohesión social, pasando de estar asociado en su origen a las clases obreras como estandarte del sindicalismo mexicano, para después ser propiedad del Grupo Televisa, una de las empresas más poderosas del país.

La visión desde la Geografía Política le permite comprender la complejidad de los desplazamientos espaciales del capital como una estrategia para cimentar los intereses de una élite local en el estado de Aguascalientes a través del análisis geohistórico del equipo del Necaxa. Si bien los resultados deportivos del equipo no han sido los deseados, los cambios de sede han permitido que quienes los promovieron activamente se hayan beneficiado alcanzando posiciones de poder y generar capital social, político y simbólico, proceso que no ha estado exento de resistencias y fracasos, lo cual evidencia la complejidad de este tipo de estrategias con dimensiones espaciales, siendo un ejemplo de cómo ciertos procesos geográficos e históricos "se moldean en gran parte por los grupos hegemónicos y las resistencias territoriales que encuentren" (p.216), en este caso para proyectar a la ciudad como un espacio moderno y atrayente para distintos tipos de inversiones.

Este libro representa de forma muy concreta una radiografía de la actualidad de la Geografia Política mexicana. Los autores abordan cuestiones y temáticas muy diversas que tienen como elemento común el análisis de las expresiones espaciales de las relaciones de poder a distintas escalas que permite deslindarla metodológi- 
camente y analíticamente de la geopolítica además de ser indicativo de su utilidad en el análisis de las problemáticas sociales.

Por lo anterior, se convierte en una obra de gran interés y de consulta recomendada para los estudiantes y profesionales de la Geografía tanto mexicanos como de otros países, fomentando de esta manera el debate y el intercambio de ideas que tan necesario es en el desarrollo de esta disciplina. La tarea que queda pendiente para los lectores es inspirarse con estos ejemplos y continuar con este tipo de esfuerzos colectivos e interdisciplinarios, cuyo objetivo sea el estudio y análisis de procesos y fenómenos complejos que caracterizan a la sociedad actual.

Juanalberto Meza Villegas

Facultad Latinoamericana de Ciencias Sociales, México

Email: juanalberto.meza@estudiante-flacso.mx 